\title{
Gestão Ambiental Portuária \\ Desafios, Possibilidades e Inovações em um Contexto de \\ Globalização
}

\section{Port Environmental Management Challenges, Possibilities and Innovations in a Globalization Context}

\author{
Dione lara Silveira Kitzmann \\ FURG \\ Rio Grande, RS, Brasil \\ Milton Lafourcade Asmusii \\ UFSC \\ Florianópolis, SC, Brasil \\ Pedro Henrique Wisniewski Koehleriii \\ IBAMA \\ Rio de Janeiro, RJ, Brasil
}

\begin{abstract}
Resumo: A atividade portuária, caracterizada como um sistema ambiental portuário, possui uma importância destacada no âmbito das zonas costeiras em que se insere. A elevada capacidade de controlar ou influenciar atividades que correm na mesma área geográfica faz com que os portos gerem impactos ambientais positivos e negativos significativos. Tal importância relativa e a constatada expansão observada do setor portuário brasileiro geram a necessidade de que suas atividades sejam ordenadas por iniciativas de Gestão Ambiental Portuária (GAP), em fase com padrões ambientais internacionalmente aceitos. O presente artigo discute elementos aninhados no conceito da gestão ambiental portuária, tendo em conta a nova realidade portuária brasileira e algumas referências modelares internacionais, referentes a ações ambientalmente adequadas para o setor. $\mathrm{Na}$ análise realizada, são tomadas em conta considerações atreladas às novas propostas tecnológicas internacionais e à realidade da política portuária brasileira. Nesse contexto, o porto de Rio Grande, Rio Grande do Sul, foi trabalhado como um estudo de caso, exemplificando sua estrutura e o modelo de gestão ambiental portuária que tenta implementar.
\end{abstract}

Palavras-chave: gestão ambiental, porto de Rio Grande, política portuária

\footnotetext{
i Professora adjunta do Instituto de Oceanografia da Universidade Federal do Rio Grande (FURG).

ii Professor visitante/Programa de Pós-graduação em Geografia - CFH/Universidade Federal de Santa Catarina; www.miltonasmus.com.br; docasmus@gmail.com

iii Oceanógrafo do Instituto Brasileiro do Meio Ambiente e dos Recursos Renováveis, Coordenação Geral de Petróleo e Gás/CGPEG.
} 
Kitzmann, D. I. S.; Asmus, M. L. e Wisniewski, P. H.

\begin{abstract}
Port activity within an overall port environmental system encompassing the whole coastal area in which ports are situated constitutes an important analytical tool. The considerable potential for controlling and influencing activities that occur in the same geographical area means that ports generate significant positive and negative environmental impacts. This importance and the significant expansion of the Brazilian port sector in recent years gave rise to the need for Port Environmental Management (GAP) based on internationally accepted environmental standards. This article discusses nested elements in the concept of port environmental management which take into account new realities of Brazilian ports as well as international standards concerning environmentally appropriate measures for the sector. New international technical proposals are discussed with regard to Brazilian port policy and the port of Rio Grande (Rio Grande do Sul State) is used as a case study, highlighting its structures and the model of port environmental management being implemented.
\end{abstract}

Keywords: environmental management, the port of Rio Grande, port policy

\title{
Introdução
}

Este artigo trata de aspectos da Gestão Ambiental Portuária (GAP), focando em uma análise dos principais desafios e dificuldades para a sua implementação e execução nos portos brasileiros. Além disso, busca caracterizar as oportunidades para o seu estabelecimento em um momento nacional de modernização e expansão dos sistemas portuários e em um contexto internacional de globalização.

Portos são locais onde vários impactos ambientais reais ou potenciais são observados com frequência. Eles podem ter um caráter positivo ou negativo, e geralmente possuem uma dimensão considerável, já que envolvem processos importantes, devido a sua intensidade e localização em áreas costeiras de elevada importância ambiental. Impactos ambientais positivos podem ser exemplificados por uma eventual melhoria na atividade pesqueira promovida pela instalação de um porto voltado para uma frota especializada, que permita introduzir avanços tecnológicos favoráveis à gestão da atividade. Da mesma forma, a instalação de um sistema portuário pode garantir a navegabilidade de um estuário pelo estabelecimento de molhes associados com programas de dragagem. Por outro lado, portos podem gerar importantes impactos ambientais negativos relacionados com a perda da qualidade ambiental (água, sedimentos ou ar), comprometimento da produção natural ou perda de valores cênicos em seu sítio de localização. A perda de qualidade pode ser produzida, por exemplo, por uma contaminação da água por vazamentos de combustíveis ou lubrificantes de navios ou pelo descarte de água de lastro. Problemas de produtividade podem ocorrer com um aumento da turbidez da água gerado pela atividade de dragagem, onde sedimentos em suspensão podem reter a luz solar necessária para a produção orgânica realizada pelo fitoplâncton. Da mesma maneira, a produção pode ser reduzida quando ambientes naturalmente produtivos, como manguezais ou marismas, são removidos para dar lugar a instalações portuárias. Finalmente, portos podem comprometer, devido a eventuais estruturas construídas ou atividades, alguns valores paisagísticos anteriormente utilizados para turismo, lazer ou educação (ASMUS et al., 2015). 
O processo de reformas do setor portuário, deflagrado pela Lei de Modernização dos Portos (Lei 8.630/93), que constituiu o chamado "novo modelo portuário brasileiro", não contemplou de forma decisiva a questão ambiental. Por não ser considerada um fator estratégico na grande complexidade das reformas pretendidas, a dimensão ambiental entrou no sistema pela via judicial, geralmente resultante de demandas do Ministério Público. Como consequência, mesmo passados tantos anos da promulgação da Lei de Modernização dos Portos, poucas autoridades portuárias têm unidades ambientais adequadamente estruturadas, com pessoal qualificado e em número suficiente, orçamento próprio e políticas consistentes e continuadas. Da mesma forma, poucas empresas privadas do sistema portuário tratam as questões ambientais no âmbito do planejamento, como uma estratégia proativa, que reduz custos e diminui impactos ambientais, evitando as ações de comando e controle que são reativas, dispendiosas e ineficazes em termos socioambientais. Ao contrário, em muitos casos essas são preocupações ainda restritas ao setor jurídico, visando o cumprimento da exigente legislação ambiental.

Portanto, é urgente o estabelecimento de um sistema de gestão ambiental nos portos brasileiros com base em políticas e princípios que privilegiem o desenvolvimento portuário com eficiência, adequação ambiental e compromisso social. Essa Gestão Ambiental Portuária - GAP - deve se estabelecer de forma transparente e com a participação permanente dos vários atores sociais que compõem o sistema portuário e ter como meta final o controle ou a mitigação dos impactos ambientais negativos e a busca de um porto sustentável (CUNHA et al., 2012; LOURENÇO; ASMUS, 2015).

\section{A Necessidade de uma Gestão Ambiental Portuária}

A gestão ambiental é um conjunto de programas e práticas administrativas e operacionais voltados à proteção do ambiente e à saúde e segurança de trabalhadores, usuários e comunidade. Apesar dessa abrangência e importância, e de já ser um diferencial competitivo em vários setores da economia, a gestão ambiental ainda é pouco desenvolvida no sistema portuário brasileiro (porto e retroporto), e, segundo Porto e Teixeira (2002), ainda "há muito por fazer para incorporar a visão ambiental no dia a dia do porto".

Para se fazer gestão ambiental é essencial preparar-se, qualificar-se, investir, mudar estruturas, processos e rotinas. É por isto que, do ponto de vista dos empreendedores, geralmente preocupados com o lucro imediato, a gestão ambiental sempre foi identificada como custo adicional. No entanto, essa lógica vem sendo superada por outra, que identifica a preservação ambiental como fator de vantagem competitiva sustentável, especialmente quando somada às ações de responsabilidade social corporativa.

As agendas ambientais, somadas às agendas comerciais, corroboram as ideias de Michael Porter e Class Van der Linde (1995, apud YOUNG e LUSTOSA, 2000), os quais avaliam que a inovação tecnológica afeta os custos e diferencia os produtos, determinando a vantagem competitiva de um concorrente sobre os demais. Assim, a regulamentação ambiental, que tem sido considerada como um fator que afeta a competitividade das empresas e dos países (visão tradicional), também pode ser um fator que a impulsiona (abordagem revisionista). De acordo com a visão tradicional, que ainda prevalece em muitos setores, as medidas de controle ambiental são barreiras ao desenvolvimento, pois 
Kitzmann, D. I. S.; Asmus, M. L. e Wisniewski, P. H.

demandariam custos elevados de adaptação, que se refletiriam nos preços dos produtos e serviços, reduzindo a competitividade das empresas.

Por sua vez, a abordagem revisionista, também denominada de "Hipótese de Porter", considera que a imposição de padrões ambientais estimula a busca de inovações tecnológicas para uma melhor utilização (e reutilização) dos insumos (matérias-primas, energia e trabalho). Isso reduziria os custos e compensaria os investimentos na adequação ambiental, melhorando a competitividade das empresas, em um círculo virtuoso de "melhoria contínua", o qual, segundo Hart (2006), deve ser sucedido pela "destruição criativa", conceito que indica o padrão dinâmico por meio do qual novas empresas inovadoras desbancam as estabelecidas (SCHUMPETER, 1934 apud HART, 2006).

A "Hipótese de Porter" mostra uma inversão da lógica que tem preponderado até o momento. A nova lógica, que poderá se constituir em um novo paradigma, considera a poluição como um sinal de ineficiência produtiva e de desperdício, não uma inevitabilidade inerente ao processo, encarando as regulamentações ambientais como oportunidades de melhoria e de novos negócios.

O aumento de produtividade pela diminuição dos impactos ambientais deve ser examinado por meio da Análise do Ciclo de Vida do produto, uma ferramenta que avalia os impactos ambientais desde a extração das matérias-primas até o descarte final destas (YOUNG; LUSTOSA, 2000). Podemos considerar que os portos fazem parte do ciclo de vida dos produtos que por eles passam (transporte e armazenamento temporário). Sendo assim, podem ser chamados a participar, por exemplo, da certificação ambiental de empresas exportadoras e importadoras. Além disso, podem sofrer os reflexos da aplicação de barreiras técnicas (não tarifárias), como os Procedimentos Aduaneiros Especiais, que exigem o ingresso de importações por meio de portos ou aeroportos específicos (MDIC, 1999; FORNASARI; COELHO, 2002). Em uma situação de competição entre portos, especialmente aqueles que estão geograficamente próximos, tais situações podem ser decisivas na escolha do que será utilizado para a movimentação de um determinado produto. Assim, os portos que estiverem ambientalmente mais adequados poderão ter uma vantagem adicional sobre os demais, tanto por diminuir impactos e custos quanto por conseguir atrair e manter determinadas cargas.

\section{O Panorama Nacional para a Gestão}

As demandas ambientais sobre o sistema portuário são imensas, por conta de passivos herdados (ambientais, culturais, estruturais) e de ativos continuamente criados. Ambos os casos geram inconformidades, que devem ser enfrentadas para que as conformidades possam ser alcançadas, garantindo o pleno funcionamento dos portos sem prejuízos econômicos e socioambientais.

O marco jurídico que regula as demandas ambientais e de segurança portuária é extenso, variando desde as convenções internacionais ratificadas pelo Brasil, até a legislação nacional e as políticas públicas estabelecidas em diferentes níveis (principalmente federal e estadual), muitas refletindo a internalização dos acordos internacionais. O cumprimento desse marco regulatório ainda é problemático, em razão da falta de conscientização, ausência de condições de infraestrutura, recursos financeiros, tecno- 
logias e pessoal capacitado, tanto por parte dos regulados (o setor portuário) quanto dos reguladores (órgãos públicos intervenientes). As principais conformidades a serem atendidas atualmente pelos portos são as Licenças de Operação (LO), licenciamento de dragagem, instalação de unidades ambientais, Plano de Emergência Individual (PEI), Plano de Gerenciamento de Resíduos Sólidos (PGRS), Auditoria Ambiental, Programa de Gerenciamento de Riscos, Plano de Controle de Emergência, Programa de Prevenção de Riscos Ambientais e o controle e monitoramento ambiental.

A Agência Nacional de Transportes Aquaviários - ANTAQ realizou uma avaliação do panorama da conformidade ambiental dos portos organizados, em que foram analisadas as ações das autoridades portuárias e terminais privativos dos trinta principais portos nacionais (ANTAQ, 2004). A situação mostrou avanços em certas áreas e a continuação de dificuldades em outras. O licenciamento de dragagem, por exemplo, estava aprovado na maior parte dos portos (86\%). No entanto, a dragagem de manutenção do porto de Santos, o maior porto brasileiro, estava suspensa na época e só foi autorizada em janeiro de 2006, devido à contaminação dos sedimentos a serem dragados. Situação resultante, em grande parte, das atividades do complexo industrial de Cubatão, localizado na parte superior do estuário de Santos.

Conforme o panorama apresentado pela ANTAQ, 90\% das autoridades portuárias já têm algum tipo de unidade ambiental para gerenciar tais questões, e 96\% já tinham encaminhado para análise os seus PGRS. Por outro lado, os menores índices de conformidade estavam relacionados com as licenças de operação, os planos de emergência individuais e as auditorias ambientais. Neste último caso, havia um baixo índice de cumprimento, pois somente $23 \%$ dos portos organizados as tinham realizado, apesar de estas serem obrigatórias e dos prazos já estarem esgotados. Isso está sendo creditado ao fato dos portos e terminais terem sido obrigados a desviarem esforços humanos e orçamentários para o cumprimento das normas do Código Internacional de Proteção de Navios e Instalações Portuárias - ISPS Code. Tais normas foram internalizadas no Brasil por este ser um dos 162 países signatários da Convenção Internacional para a Salvaguarda da Vida Humana no Mar - Convenção SOLAS, de 1974, que passou por uma minuciosa revisão e atualização após os atentados de 11 de setembro de 2001.

Considerando as adequações a LO e PEI, foi constatado que as autoridades portuárias estavam mais atrasadas no seu cumprimento do que os terminais privativos. Somente $38 \%$ delas estavam licenciadas, o que contrasta com o percentual de $73 \%$ observado nos terminais arrendados ao setor privado. O mesmo se repete com o PEI, aprovado em somente $29 \%$ das autoridades portuárias e em $69 \%$ dos terminais arrendados.

Esse panorama mostra um quadro preocupante, em especial porque o crescimento acumulado do comércio exterior brasileiro entre 2001 e 2005 foi de 68,5\% (HIJJAR; ALEXIM, 2006), evidenciando uma maior pressão do sistema portuário e do sistema de transporte como um todo. Além de todas as dificuldades ocasionadas pelos problemas de logística, decorrentes dos crônicos problemas da infraestrutura de transportes, acrescente-se o baixo atendimento às conformidades ambientais, o que pode trazer restrições aos produtos nacionais. O quadro presente resulta de uma herança da implantação de políticas equivocadas no passado, configurando o que poderíamos chamar de um passivo estatal, que tem características sociais, pelo desemprego e precatórios trabalhistas não pagos; tecnológicas, pelo sucateamento das estruturas; financeiros, pelas dívidas 
Kitzmann, D. I. S.; Asmus, M. L. e Wisniewski, P. H.

trabalhistas das companhias docas; e gerenciais, devido à falta de pessoal e a modelos de gestão ultrapassados. Esse quadro contribuiu decisivamente para a formação do passivo ambiental em nossos portos, situação exemplificada pelo abandono e disposição inadequada de cargas perigosas no porto do Rio Grande, RS (TAGLIANI; ASMUS, 1997).

Ambos os passivos, estatal e ambiental, devem ser superados o mais rápido possível, já que o papel dos portos no novo modelo portuário nacional, um ambiente de extrema competição, exige velocidade na tomada de decisões e implementação de soluções, assim como uma nova postura ambiental (ROMERO et al., 2014).

\section{Ações Políticas no Âmbito da GAP}

A desestruturação da máquina pública determinada pela reforma do estado brasileiro na década de 1990, em que esteve inserido o processo de reformas portuárias, gerou problemas estruturais nos organismos reguladores governamentais, que dificultam o acompanhamento e a fiscalização das atividades portuárias. Não há técnicos em número suficiente, gerando sobrecarga de trabalho, assim como não há qualificação para o exercício de funções que exijam conhecimentos específicos do setor portuário e de suas relações com o meio ambiente. Há superposição de competências e predomínio de enfoques parciais (setoriais) em matéria ambiental, de gerenciamento costeiro e de desenvolvimento regional. Os diversos órgãos reguladores têm dificuldades para compatibilizar suas agendas de trabalho e integrar políticas e ações, devido a visões conflitantes do funcionamento do sistema portuário e das causas e soluções para os problemas ambientais ali gerados. Outro fator a destacar é a inconsistência das ações de regulação, que variam de porto a porto. Assim, de acordo com características locais, um porto pode ser regulado pelo órgão estadual de proteção ambiental e não pelo órgão federal, mais atuante em outros portos, ou por ambos (como o caso do Porto do Rio Grande). Isso resulta da falta de uma política nacional para o setor, que seja aplicada de forma harmônica em todos os portos, respeitando, é claro, as características específicas de cada sítio portuário, que exigem diferentes estratégias de gestão.

Há uma grande quantidade de órgãos governamentais (autoridades aduaneira, marítima, ambiental, sanitária, de saúde, de polícia marítima), regulando a atividade portuária, distribuídos em vários ministérios, com funções não claramente definidas, gerando superposição de competências e enfoques não integrados de gestão. Há dificuldades em compatibilizar as agendas de trabalho e harmonizar as ações, uma vez que os órgãos têm visões diferentes do sistema portuário, de seu funcionamento e das causas e soluções para os problemas ambientais (ASMUS et al., 2005). Seguidamente, quando um destes conhece o sistema portuário, desconhece as questões ambientais, e vice-versa. Além disso, cada órgão tem a sua própria estrutura, funcionamento, cultura e agenda institucional, o que contribui para que, até agora, não tenha sido construída uma "agenda portuária", que contemple uma visão integrada de porto. Uma agenda que vise atender às necessidades de infraestrutura portuária, como a Agenda Portos (instituída em 2004, era um conjunto de 64 projetos a serem desenvolvidos nos 11 principais portos do país, prevendo dragagens e adequação de rodovias e ferrovias), mas que busque também a adequação gerencial, incluindo aí a variável ambiental. Significa dizer que deve organi- 
zar e padronizar, mas de modo flexível, tanto os procedimentos dos órgãos reguladores, quanto dos demais atores portuários.

Uma agenda com essas características deve ser fruto de um consenso amplo, em que os atores envolvidos contribuam com a sua visão de porto, que isoladamente não é completa, mas que em conjunto permitiria uma abordagem mais ampla e integrada dos problemas portuários. Além disso, dada a complexidade do sistema e as mudanças ocorridas nos últimos anos, não há instituição (governamental ou privada), ou entidade classista (patronal ou trabalhista), que tenha todas as respostas para os problemas portuários.

A solução dos problemas ambientais nas áreas portuárias é complexa, demandando um somatório de esforços de vários setores (público, privado, acadêmico), na busca de alternativas inovadoras que superem as barreiras administrativas e culturais que têm retardado a implementação de práticas mais adequadas de gestão, inclusive ambientais. Essa situação é típica de países em desenvolvimento como o Brasil, onde há pressão por maior produtividade e eficiência portuária, mas uma grande carência de recursos públicos que propiciem condições de infraestrutura e tecnologias gerenciais para atingir esse objetivo. Além disso, os escassos recursos são dirigidos para as inúmeras obras de infraestrutura necessárias, determinando que a gestão ambiental nos portos ainda não seja prioritária nos investimentos governamentais. Isso estava claramente demonstrado no Plano Plurianual - PPA (2004-2007), no qual eram previstas poucas ações de suporte à gestão ambiental portuária, ao contrário dos pesados recursos disponibilizados para a ampliação e recuperação estrutural dos principais portos, agravado pelo fato de que estes são constantemente contingenciados pelo governo federal. Nesta linha seguiu o Plano de Aceleração do Crescimento - PAC (2007-2010), que prevê investimentos de R\$ 58,3 bilhões na infraestrutura logística, dos quais os portos beneficiados receberão cerca de R\$ 2 bilhões, sendo R\$1,4 bilhão para dragagens de aprofundamento dos canais de acesso a terminais.

No entanto, como grande regulador do sistema portuário, é urgente que o setor governamental apoie ações de gestão ambiental, propiciando condições e motivando positivamente os outros componentes do sistema (operadores, usuários etc.) a fazerem a sua parte no cumprimento da regulamentação ambiental. Assim, independente de grandes recursos financeiros, o setor governamental deveria aportar outras formas de subsídios, tais como usar os seus espaços de atuação dentro do sistema para aglutinar os atores portuários em torno do que deveria ser um objetivo comum, a segurança ambiental de nossos portos e, por consequência, dos espaços urbanos e ambientais conexos. As conquistas ambientais na área portuária dependem, em grande parte, do estabelecimento e implantação de políticas específicas, como a Agenda Ambiental Portuária (CIRM, 1998). Se nos últimos anos houve melhorias na gestão ambiental nos portos brasileiros, muito se deve ao esforço individual de cada porto, frente ao pouco realizado pelo poder público nessa área. A grande diversidade de agências reguladoras da atividade portuária, ao atuarem desarticuladamente, geram conflitos de gestão, como se observa no licenciamento ambiental, na dragagem e na capacitação ambiental, entre tantas outras questões. Assim, dado o quadro presente, não é prudente esperar, no curto prazo, que as conquistas ambientais abranjam, de forma significativa, o conjunto dos portos brasileiros, ainda muito aquém do padrão internacional. 
Kitzmann, D. I. S.; Asmus, M. L. e Wisniewski, P. H.

\section{Boas Práticas e Oportunidades para a GAP - O Aporte Global}

A evolução da gestão ambiental portuária em termos mundiais tem ocorrido de forma mais destacada em portos europeus e norte-americanos, decorrentes de iniciativas multilaterais ou de gestores de um porto isolado. A American Association of Port Authorities - AAPA, que congrega mais de 150 autoridades portuárias de portos do Canadá, do Caribe, da América Latina e dos Estados Unidos, desenvolve importantes ações ambientais, entre as quais podem ser destacadas: a) a elaboração do Environmental Management Handbook (AAPA, 1998), um guia com ferramentas e práticas de gerenciamento das atividades portuárias voltadas à prevenção e remediação dos impactos ambientais do setor; e b) a criação, em 1973, do Environmental Improvement Awards, por meio do qual a AAPA reconhece e estimula as atividades que beneficiam o ambiente em seus portos, nas categorias de melhoria ambiental, mitigação, envolvimento comunitário e gerenciamento ambiental.

O porto de Long Beach, Califórnia (EUA), estabeleceu cinco princípios que deverão guiar seus esforços ambientais, quais sejam: 1) proteger a comunidade e o ambiente local dos impactos portuários negativos; 2) utilizar as melhores tecnologias disponíveis para minimizar os impactos portuários e explorar novas soluções tecnológicas; 3 ) promover a sustentabilidade nas ações relacionadas à instalação e operação dos terminais; 4) distinguir o porto como um líder ambiental e de cumprimento da legislação; e 5) engajar e educar a comunidade sobre o desenvolvimento do porto e seus programas ambientais.

Uma boa prática de GAP foi desenvolvida pelo "EcoPorts Project", um projeto de pesquisa da União Europeia cujos objetivos foram harmonizar a gestão ambiental entre os seus portos, trocar experiências e implementar as melhores práticas ambientais portuárias. Desenvolvido entre 2002 e 2005, envolveu pelo menos 150 portos e terminais europeus em uma rede ambiental, e os principais produtos desenvolvidos foram: a) Metodologia de Auto-Diagnóstico (Self-Diagnosis Method - SDM), ferramenta de autoavaliação ambiental, identificação de prioridades e do nível de resposta gerencial na área portuária e na cadeia logística; b) Sistema de Revisão Ambiental Portuária (Port Environmental Review System - PERS), que ajudará os portos a executarem os primeiros passos de um Sistema de Gestão Ambiental (Environmental Management System - EMS) e certificações, como a ISO 14000; c) base de dados sobre boas práticas e estudos de caso exemplares; d) programa de treinamento, com cursos adaptados às perspectivas locais e nacionais quanto à legislação e condições operacionais, cujos instrutores são profissionais portuários e especialistas acadêmicos certificados; e) workshops: organizados para a troca e implementação de experiências e melhores práticas ambientais; f) Pesquisa: há uma rede de universidades e consultores para prestar serviços multidisciplinares de pesquisa e desenvolvimento de soluções ambientais.

Após o término do "Ecoports Project", a Fundação Ecoports (estabelecida em 1999 por um grupo de oito portos europeus e que foi a origem do referido projeto) está dando prosseguimento à "abordagem Ecoports", apoiando a continuidade dos produtos e serviços ali desenvolvidos.

Em termos de União Europeia, uma avaliação da gestão ambiental em seus portos (ESPO, 2005), identificou que $86 \%$ destes têm ou estão desenvolven- 
do uma política ambiental; 59\% a tornavam disponível ao público; 49\% desenvolviam planos de gestão ambiental com padrões além dos requeridos pela legislação; e 69\% promoviam, através destes planos, a conscientização ambiental entre os usuários do porto. Dentre os portos pesquisados, 67\% tinham uma equipe ambiental específica e 58\% garantem a capacitação ambiental destas equipes. Quanto à gestão ambiental, 65\% realizam monitoramento na área portuária e 48\% já definiram indicadores ambientais, básicos para o acompanhamento da evolução da gestão. Mesmo não consistindo em soluções definitivas, já existem inovações que são essenciais para a sustentabilidade do comércio marítimo e que demonstram os desafios e as possibilidades de mudanças conceituais e de avanços tecnológicos na área da gestão ambiental portuária. Exemplos de tais inovações, ou eco-inovações, abrangem tanto os contêineres quanto os navios que os transportam. (ESPO, 2013)

\section{Ecocontêineres}

Em razão do incremento do comércio mundial, particularmente devido à atuação da China, a demanda por contêineres tem crescido 11,5\% ao ano, de forma que o consumo de madeira, utilizada para a construção dos seus pisos, é cada vez maior. Após alguns anos de pesquisa, o substituto eleito foi o bambu, que alcança o tamanho ideal em 4-5 anos, pode ser cultivado e tem grande capacidade de regeneração. O piso compensado feito com bambu mantém as características de resistência, umidade e infestação de insetos, com o mesmo tempo de vida (10-12 anos) do piso usual e com um custo 5\% menor. Considerando o alerta de Hart (2006) de que a maioria das tecnologias verdadeiramente sustentáveis tende a ser inovadora, mas que nem todas as tecnologias inovadoras serão sustentáveis, deve-se tomar o cuidado para não causar impactos ambientais na extração do bambu e nem na fabricação do compensado.

\section{Econavios}

Outro exemplo de ecoinovação vem do setor de construção naval, que já fabrica navios contenedores de 300 metros de comprimento alinhados com os mais avançados conceitos e normas de segurança ambiental. Devido às ecoinovações para a contenção de águas residuais e a diminuição das emissões aéreas, os chamados "green ships" terão casco duplo e tanques colocados em áreas mais protegidas, visando minimizar o risco de derrame de óleo ou incêndio após um encalhe ou colisão. Além disso, terão separadores de água e óleo de maior capacidade de armazenamento de águas residuais. Com isso evitarão a descarga em áreas sensíveis, levando os resíduos oleosos até as estruturas de tratamento nos portos. Quanto às emissões aéreas, são duas as adaptações. Há a possibilidade do uso de tanques segregados (de até 8,3 mil toneladas) para combustível com baixos teores de enxofre, atendendo ao Anexo VI da MARPOL, que obriga que os navios operem com tais combustíveis nas áreas sensíveis definidas por esta norma, como é o caso do Mar Báltico. Outra ecoinovação para diminuir as emissões aéreas é a "cold ironing", que permite ao navio desligar os seus geradores a diesel quando atracado (usados para refrigeração, luzes, bombas e outras funções) e receber energia elétrica das estruturas portuárias. 
Kitzmann, D. I. S.; Asmus, M. L. e Wisniewski, P. H.

\section{Interface Econavios e Portos}

As inovações que estão sendo incorporadas aos navios irão pressionar por adequações nas estruturas e sistemas de gestão nos portos, que precisarão estar preparados para atender àquelas. O porto de Long Beach (Califórnia, EUA) implementou um "Programa de Melhoria da Qualidade do Ar", cujo objetivo é obter reduções na poluição aérea, em especial nas emissões oriundas das operações portuárias. Suas ações extrapolam as exigências dos órgãos reguladores, uma vez que buscam reduzir emissões dos arrendatários e dos equipamentos do porto, assim como de outras fontes, as chamadas "off-road", pouco controladas pelos órgãos ambientais e que incluem até as locomotivas que operam na área portuária. Há exemplos na Europa sobre a utilização de instrumentos econômicos de incentivo à diminuição de emissões pelos navios. As taxas portuárias cobradas pelo governo sueco são menores para as embarcações que disponham de tecnologias de redução de óxidos de nitrogênio (NOx), assim como para aquelas que utilizem combustível com baixo teor de enxofre. Outras medidas que recompensam as baixas emissões navais são o "Green Award" (em vigor em 35 portos, que oferece incentivos ao desempenho ambiental), o "Green Shipping Bonus" (implementado pelo porto de Hamburgo em 2001, que oferece desconto aos navios sobre as taxas portuárias) e a "diferenciação do imposto de tonelagem de acordo com critérios ambientais" da Noruega.

A motivação para o desenvolvimento dessas ecoinovações é claramente econômica, com diminuição de custos e de atendimento da norma ambiental, tratando-se de uma estratégia de sobrevivência no mercado. No entanto, em que pesem as motivações das agendas comerciais, o fato concreto é que esses exemplos representam mudanças no trato das questões ambientais e trazem benefícios que se estendem à coletividade

\section{A Gestão Ambiental Portuária como um Sistema Operacional e Político: O Caso do Porto do Rio Grande, RS}

O Porto do Rio Grande, no estado do Rio Grande do Sul, pela sua importância estratégica no Mercado Comum do Sul (MERCOSUL) e pelo seu destaque econômico no sul do Brasil, é um componente maior entre os que compõem o conjunto de sistemas portuários no país. É também significativo o fato de que o porto do Rio Grande foi o primeiro porto organizado brasileiro a obter e manter uma licença de operação (LO) por meio do Ibama (em 1997) (LOURENÇO; ASMUS, 2015). A seguir são descritos e comentados alguns aspectos de seu Sistema Ambiental Portuário.

A apresentação do sistema de gestão ambiental portuária ora realizado é embasada em um modelo geral, que envolve os componentes e processos centrais do sistema. Em seguida são descritos os principais processos identificados, que na prática se materializam por meio de ações específicas de controle, minimização e monitoramento de impactos ambientais executadas pela autoridade portuária, terminais e instalações. Em Rio Grande a gestão ambiental portuária ocorre em um panorama institucional complexo, no qual diversas organizações interagem com base em objetivos e funções próprias. Nesse panorama - também caracterizado pela extrema competitividade e importância no 
cenário econômico - a gestão ambiental é viabilizada principalmente pelos instrumentos de comando e controle e em menor grau por instrumentos econômicos ou de mercado.

De acordo com a lógica de comando e controle, os componentes do sistema de gestão ambiental foram divididos em duas categorias principais: aqueles que exercem o papel de reguladores e aqueles que são regulados. As agências estatais de controle ambiental, segurança marítima e vigilância sanitária exercem o papel de reguladores, enquanto que os terminais, as instalações, os operadores e responsáveis pelas instalações portuárias figuram como componentes regulados. A particularidade interessante desse recorte diz respeito à autoridade portuária, que tem o dever de exercer ambos os papéis ao mesmo tempo, segundo suas atribuições legais. O Ministério Público também apresenta um caráter diferenciado, pois regula a atuação dos agentes privados e órgãos públicos, buscando garantir o cumprimento da legislação e as obrigações de cada componente.

Os instrumentos de mercado também interferem na dinâmica do sistema e, apesar de não exercerem diretamente a regulação, são capazes de provocar mudanças em determinados componentes, a partir da ótica da certificação ambiental e diferencial competitivo. Outros componentes presentes correspondem a organizações auxiliares, que atuam junto aos agentes regulados nos processos de adequação ambiental. Nessa classe se encontram a universidade, empresas de consultoria, auditores e prestadores de serviço. A Figura 1 apresenta um diagrama do sistema de gestão ambiental do porto.

Figura 1 - Modelo do sistema de gestão ambiental portuário do Rio Grande

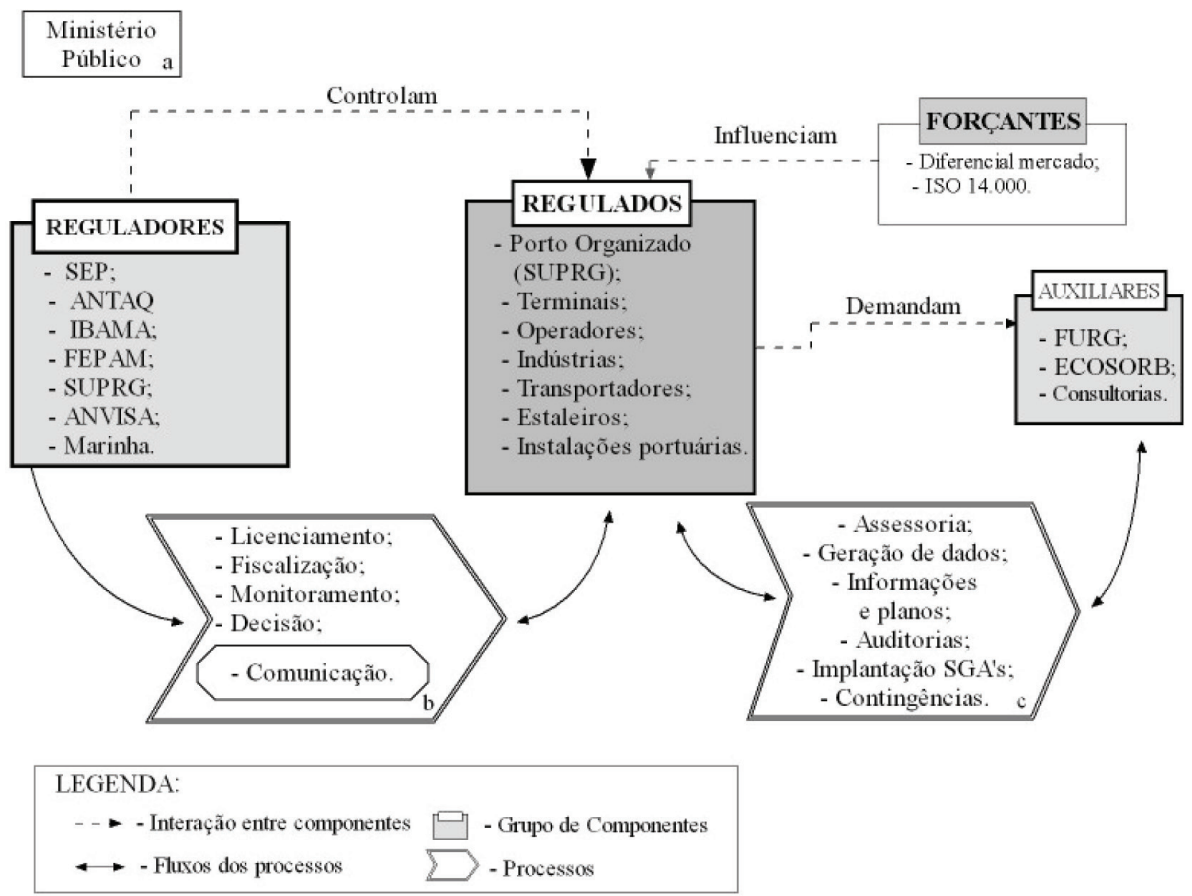

Fonte: reproduzido de Koehler (2008). 
Kitzmann, D. I. S.; Asmus, M. L. e Wisniewski, P. H.

Os principais processos envolvem a interação entre os componentes reguladores e regulados do sistema e estão representados no diagrama pela caixa $b$. Consistem do licenciamento ambiental, fiscalização, monitoramento e também processos transversais de tomada de decisão. Um segundo rol de interações envolve as relações entre os regulados e auxiliares (representados pela caixa c), como auditorias ambientais, planejamento, produção de informações, contingenciamento de acidentes e implantação de Sistemas de Gestão Ambiental. Um detalhamento maior dos processos indica que as interações existentes entre os reguladores e regulados podem ser descritas da seguinte forma:

\section{Licenciamento ambiental}

É o principal processo que mobiliza o sistema como um todo. As três fases do licenciamento (licença prévia, de instalação e operação) buscam pautar a localização, construção e funcionamento dos portos com base em avaliações de impacto ambiental e diretrizes de planejamento ambiental. O licenciamento envolve a análise de estudos ambientais e o acompanhamento do cumprimento das exigências durante o processo, por meio de vistorias e trocas de informações. O procedimento resulta na emissão da licença que define as condicionantes particulares que cada empreendimento deve observar e cuja fiscalização cabe aos órgãos ambientais.

\section{Fiscalização}

As ações de fiscalização, tomadas como um procedimento de rotina, correspondem a outro processo importante que compõe o sistema. A Agência Nacional de Vigilância Sanitária (ANVISA) se ocupa das questões sanitárias dentro dos navios que acostam e nas áreas primárias do porto, assim como do gerenciamento de resíduos sólidos, enquanto que os órgãos ambientais fiscalizam o atendimento à legislação ambiental e o cumprimento das condicionantes das licenças. A fiscalização pressupõe a aplicação de sanções no caso de não conformidades, podendo ser advertências ou multas ambientais. Tais sanções visam corrigir a operação do sistema de gestão e decorrem do poder de polícia administrativa exercido pelos órgãos reguladores.

\section{O monitoramento ambiental}

É o resultado de uma exigência da Licença de Operação do Porto Organizado prevista na Resolução CONAMA n 237/97, na qual o IBAMA exige o acompanhamento de parâmetros oceanográficos de qualidade ambiental por parte da Superintendência do Porto do Rio Grande (SUPRG). A SUPRG, por sua vez, recorre à expertise técnica existente na universidade local (Universidade Federal do Rio Grande - FURG), que executa o levantamento das informações mediante convênio entre ambas as instituições. As informações são encaminhadas para a análise do IBAMA, que, desta forma, mantém um acompanhamento das condições ambientais da região monitorada.

\section{A tomada de decisão}

Na realidade, esse é um procedimento transversal, relacionado aos demais processos, e envolve escolhas relativas à localização de empreendimentos, definição de aspectos 
ambientais relevantes, minimização de riscos, controle de dragagens e outras intervenções, assim como a aplicação de sanções cabíveis, previstas na legislação ambiental. O segundo conjunto de processos da Figura 1 envolve os componentes regulados e os auxiliares, em que as principais interações podem ser descritas como:

\section{Geração de informações}

Correspondem às informações que subsidiam os processos de licenciamento, tais como a geração de laudos do meio físico, biológico e socioeconômico, relatórios ambientais e monitoramento dos programas ambientais exigidos nas licenças. O monitoramento dos parâmetros ambientais também faz parte desses processos.

\section{Planejamento}

Elaboração de produtos exigidos pela legislação, como no caso dos Planos de Emergência Individuais (PEI), Planos de Contingência e Planos de Gerenciamento de Resíduos Sólidos. A elaboração de Planos de Gestão Ambiental Integrada também pode ser delegada às componentes auxiliares do sistema.

\section{Auditorias ambientais}

São aquelas exigidas pela Resolução CONAMA n 306/02 para instalações portuárias, assim como auditorias dos sistemas de gestão ambiental (ISO 14.000) e de certificação por outros órgãos também são conduzidas por organizações auxiliares.

\section{Serviços técnicos/consultoria}

Apresentam-se em variadas formas (legislação, engenharia, controle ambiental, planejamento organizacional), visando à adequação dos empreendimentos às exigências dos órgãos reguladores, assim como a execução de programas ambientais internos e interlocução com os órgãos de controle.

\section{Contingenciamento}

Ações de contenção em caso de derrames ou acidentes com óleos, combustíveis e produtos perigosos, envolvendo o controle de vazamentos, contenção, recuperação do material e limpeza de áreas afetadas. Para melhor compreender as relações de regulação é importante fazer a distinção entre as competências de licenciamento ambiental no contexto do porto do Rio Grande. A regulamentação desse tema ainda necessita de avanços, pois não há uma definição clara em nível nacional sobre as competências do licenciamento das atividades portuárias. A aplicação desse instrumento tem sido conduzida por diferentes esferas de governo, havendo sobreposição de procedimentos distintos e falta de articulação visando ao gerenciamento integrado das atividades (AGRA-FILHO, 2005). A Tabela 1 representa, de maneira geral, as competências de licenciamento e controle das atividades relacionadas ao porto do Rio Grande. 
Kitzmann, D. I. S.; Asmus, M. L. e Wisniewski, P. H.

Tabela 1 - Competências de licenciamento no porto do Rio Grande, RS

\begin{tabular}{|l|l|}
\hline ÓRGÃO LICENCIADOR & \multicolumn{1}{|c|}{ EMPREENDIMENTOS LICENCIADOS } \\
\hline \multirow{4}{*}{ IBAMA } & - Aprofundamento do canal (SEP-PR); \\
\cline { 2 - 3 } & - Prolongamento dos molhes da barra (DNIT); \\
\cline { 2 - 3 } & - Superintendência do Porto do Rio Grande (SUPRG). \\
\hline \multirow{4}{*}{ FEPAM } & - Terminais; \\
\cline { 2 - 2 } & - Instalações portuárias; \\
\cline { 2 - 2 } & - Operadores; \\
\cline { 2 - 3 } & - Depósitos/Armazéns; \\
\cline { 2 - 2 } & - Serviços técnicos; \\
\cline { 2 - 2 } & - Indústrias retroportuárias. \\
\hline
\end{tabular}

O Ibama licencia a operação na área do Porto Organizado e também as obras de ampliação dos molhes da barra (sob responsabilidade do Departamento Nacional de Infraestrutura dos Transportes - DNIT) e aprofundamento do canal de navegação (obra da Secretaria Especial de Portos - SEP, da presidência da República). O órgão ambiental estadual, no caso a Fundação Estadual de Proteção Ambiental (FEPAM), licencia os terminais, indústrias, operadores e demais instalações. Nesse sentido, a Licença de Operação do IBAMA nº 03/1997 - concedida à SUPRG e renovada em 2005 pelo prazo de oito anos - estabelece como condicionante a elaboração de um Plano de Gestão Integrada que defina as atribuições da autoridade portuária, das instalações portuárias e dos terminais na área do Porto Organizado. Esse plano deve dar base à estruturação de um Sistema de Gestão Integrada, com estrutura administrativa de coordenação e implementação, com organograma e definição de hierarquia e atribuições. Tal instrumento foi concebido no sentido de exercer um papel de articulação entre as exigências feitas pelos componentes reguladores do sistema (no caso, Ibama e Fepam), auxiliando o atendimento das demandas colocadas aos componentes regulados.

É interessante notar que, mesmo no caso do porto do Rio Grande, são muitas as dificuldades para o completo cumprimento, por parte da autoridade portuária, das condicionantes referentes à sua licença ambiental. Apesar de tomado como referência nacional devido ao seu licenciamento ambiental, há ainda um amplo espaço para o crescimento de uma estrutura adequada para a sua gestão ambiental (física e de pessoal) e para o maior desenvolvimento dos instrumentos de suporte à gestão, tais como os planos de planejamento territorial da área portuária e planos de gestão ambientais integrados. Tais planos podem, em princípio, incorporar muitas das inovações aqui comentadas e avançar para um sistema moderno de gestão ambiental.

É preciso que os portos brasileiros se integrem ao novo paradigma mundial de gestão portuária. Somente assim haverá coerência com o processo de modernização instituído pela Lei 8.630/93, que buscava portos eficientes e competitivos. Afinal, quem adotou a modernidade da privatização deve ser coerente e também adotar a modernidade da sus- 
tentabilidade, nas suas dimensões ambiental, econômica e social. Da mesma forma que os portos não devem estar isolados da realidade comercial de seus usuários, também não devem estar desconexos dos processos sociais e ambientais que ocorrem no seu interior e ao seu redor. Como não há nada mais moderno do que trabalhadores bem qualificados para o exercício de suas funções e não há nada mais atual (e urgente) do que a incorporação de conceitos e práticas de gestão ambiental, o processo brasileiro de modernização portuária estará incompleto enquanto não enfrentar esses desafios.

\section{Considerações Finais}

O Brasil vive um momento único quanto à importância de sua atividade portuária. A consolidação do país como exportador de recursos naturais e transformados e o esforço que o governo nacional tem empreendido no sentido de incluí-lo definitivamente no contexto de um mercado cada vez mais globalizado têm demandado o estabelecimento de um sistema portuário que deve ser eficiente e competitivo. O próprio Programa de Aceleração do Crescimento (PAC) do atual governo federal tem priorizado os portos em várias de suas ações propostas. Um bom exemplo envolve o programa de aprofundamento do calado de vários portos nacionais de destaque sob a coordenação da Secretaria Especial de Portos (SEP). São ações que, pela sua dimensão, podem produzir um impacto ambiental considerável nos sítios de localização dos portos envolvidos. O programa de aprofundamento ora em implementação está a exigir ações de dragagem em uma escala ainda não acompanhada pelos programas de monitoramento ambiental nos portos em que ocorrem. Portos mais profundos estarão aptos a receber navios maiores e, certamente, desenvolverão estruturas portuárias e retroportuárias também de maior porte e dinâmica. Da mesma forma, na tentativa de manterem a boa qualidade ambiental por questões que não são apenas legais, mas também de mercado e institucionais, essa nova realidade portuária brasileira exige um novo patamar de gestão ambiental moderna e eficiente.

Pelos exemplos comentados no texto, pode-se concluir que as oportunidades para uma boa GAP são significativas. Há, no entanto, um movimento claudicante do sistema portuário brasileiro em adotá-las institucionalmente, por razões não apenas técnicas ou de pessoal, mas que também envolvem a própria cultura portuária brasileira. É possível, mas não trivial, a adoção de novas práticas de gestão ambiental com sustentabilidade institucional, financeira e com o respaldo e apoio dos atores sociais envolvidos (trabalhadores portuários, autoridade portuária etc.). Portos como o de Rio Grande, RS, (como no caso analisado) demonstram ter estabelecido um sistema de gestão ambiental que pode ser aprimorado pela introdução de instrumentos de suporte à gestão em linha com as boas-práticas aqui comentadas.

O panorama apresentado pela agência reguladora (ANTAQ, 2004) mostra que 90\% das autoridades portuárias já têm algum tipo de unidade ambiental. Isso é um bom indicador da gestão ambiental em termos administrativos, mas será a existência e o acompanhamento de indicadores ambientais o que irá demonstrar a qualidade ambiental do entorno portuário e, por consequência, da gestão ambiental portuária. Quando tivermos parâmetros confiáveis de acompanhamento de resultados é que poderemos considerar que temos uma gestão ambiental estruturada e em pleno funcionamento. 
Kitzmann, D. I. S.; Asmus, M. L. e Wisniewski, P. H.

Chegar a esse patamar demandará um ajuste interinstitucional que deverá abranger o setor público, que deve assumir plena e corretamente o seu papel de regulador do sistema portuário (o que inclui a regulação ambiental); o setor privado, que deve assumir um papel socioambiental, ou seja, o de propiciar emprego e renda considerando a variável ambiental; e a sociedade como um todo, que deve acompanhar e fiscalizar as ações de ambos.

\section{Referências Bibliográficas}

AGÊNCIA NACIONAL DE TRANSPORTES AQUAVIÁRIOS - ANTAQ. Panorama geral da situação ambiental dos portos. Seminário EcoBrasil, 4-6/08/2004, Rio de Janeiro, RJ. 2004.

Informativo Navegando a Notícia, Brasília, n.9, setembro de 2006 (versão eletrônica).

AGRA-FILHO, S. S. Licenciamento ambiental portuário: uma proposta de integração. Gerenciamento Costeiro Integrado, Itajaí, v.4, n.3, p.1-5, 2005.

ASMUS, M. L., SCHERER, M.G., ONETTI, J.G.; ABRÃO, G.R. Gestión basada en ecosistemas para sistemas portuarios: Una propuesta metodológica para integrar la gestión de zonas costeras en Brasil. Congresso Latino-americano de Ciências do Mar (COLACMAR), Santa Marta, Colômbia, Outubro de 2015.

ASMUS, M.L.; KITZMANN, D.I.; LAYDNER, C. Gestão Costeira no Brasil: Estado Atual e Perspectivas. ENCUENTRO REGIONAL "COOPERACIÓN EN EL ESPACIO COSTERO". Montevideo, Uruguay, 28-30/09/2004. Anais do Encuentro regional "cooperación en el espacio costero" Mar del Plata: ECOPLATA/GAPAS/FREPLATA/PROBIDES, 2005. 59 p.

CMA CGM Group. CMA CGM \& The Environment. 2005, 7 p. Disponível em <www. cma-cgm.com/environment>. Acesso em: 5 nov. 2015.

Ecological containers enter the CMA CGM fleet. Press release. Marseille, June 28th 2005, 1p. Disponível em: <www.cma-cgm.com/environment>. Acesso em: 5 nov. 2015.

COMISSÃO INTERMINISTERIAL PARA OS RECURSOS DO MAR. Agenda ambiental portuária. CIRM, GI-GERCO e Sub-Grupo Agenda Ambiental Portuária. Brasília, DF, 1998, $11 \mathrm{p}$.

CUNHA, I.; ASMUS, M. L.; SCHERER, M. E. G. Linhas de evolução da gestão mbiental dos Portos na Costa Brasileira. In: I CONGRESO IBEROAMERICANO DE GESTIÓN INTEGRADA DE ÁREAS LITORALES. Libro de Comunicaciones y de Posters. Cadiz : Universidade de Cadiz, 2012. p. 305-314. 
EUROPEAN SEA PORTS ORGANIZATION - ESPO. Environmental Survey 2004. Review of European Performance in Port Environmental Management, abril 2005, 4p.

Green Guide: Towards Excellence in Port Environmental Management and Sustainability, 2013.

FORNASARI F. N.; COELHO, L. R. Aspectos ambientais do comércio internacional. São Paulo: FIESP - CIESP, dezembro de 2002. 129 p.

HART, S. L. O capitalismo na encruzilhada. As inúmeras oportunidades de negócios na solução dos problemas mais difíceis do mundo. Porto Alegre: Bookman, 2006. 232p.

HIJJAR, M. F.; ALEXIM, F. M. B. Avaliação do acesso aos terminais portuários e ferroviários de contêineres no Brasil. Rio de Janeiro: COPPEAD;UFRJ, Centro de Estudos em Logística, 2006. 10p. Disponível em: <http://www.centrodelogistica.com.br/new/fs-panorama_ logistico3.htm>. Acesso em: 15 ago. 2013.

KOEHLER, P. H. W. Sistematização dos dados de monitoramento como ferramenta de suporte ao gerenciamento ambiental do porto de Rio Grande - RS. Rio Grande, 2008. 129f. Dissertação (Mestrado em Oceanografia Física, Química e Geológica) - Universidade Federal do Rio Grande.

LOURENÇO, A. V.; ASMUS, M. L. Gestão ambiental portuária: fragilidades, desafios e potencialidades no porto do Rio Grande, RS, Brasil. Journal of Integrated Coastal Zone Management, v.15(2), p.223-35, 2015.

MINISTÉRIO DO DESENVOLVIMENTO, INDÚSTRIA E COMÉRCIO EXTERIOR - MDIC. Barreiras Externas às Exportações Brasileiras. Brasília: Secretaria de Comércio Exterior. Funcex, MDIC, 1999. 271p.

PORTO, M. M.; TEIXEIRA, S. G. Portos e meio ambiente. São Paulo: Aduaneiras, 2002, $227 p$.

ROMERO, A. F.; ASMUS, M. L. MILANELLI, J. C. C. BURUAEM, L.; ABESSA, D. M. S. Self-diagnosis Method as an Assessment Tool for Environmental Management of Brazilian Ports. Journal of Integrated Coastal Zone Management, v.14(4), p.637-44, 2014.

TAGLIANI, P. R. A.; ASMUS, M. L. (coords.). Estudo de impacto ambiental do Porto de Rio Grande, RS. Fundação Universidade Federal do Rio Grande, RS. Documento Técnico, 1997. 850p.

YOUNG, C. E. F.; LUSTOSA, M. C. Meio ambiente e competitividade na indústria brasileira. Revista de Economia Contemporânea. Rio de Janeiro, v.5, p.231-59, 2001.

Recebido em: 21/9/2014 Aceito em: 29/11/2014 
